\title{
Adsorptive Treatment of Textile Wastewater Using Activated Carbon Produced from Mucuna pruriens Seed Shells
}

\author{
Chinenye Adaobi Igwegbe ${ }^{*}$, Pius Chukwukelue Onyechi², Okechukwu Dominic Onukwuli ${ }^{1}$, \\ Ikenna Chukwudi Nwokedi ${ }^{1}$ \\ ${ }^{1}$ Department of Chemical Engineering, Nnamdi Azikiwe University, Awka, Nigeria \\ ${ }^{2}$ Department of Industrial and Production Engineering, Nnamdi Azikiwe University, Awka, Nigeria \\ Email: "chinenyeigwegbe@gmail.com
}

Received 6 October 2015; accepted 11 January 2016; published 18 January 2016

Copyright (C) 2016 by authors and Scientific Research Publishing Inc.

This work is licensed under the Creative Commons Attribution International License (CC BY). http://creativecommons.org/licenses/by/4.0/

(c) ()

\begin{abstract}
Mucuna pruriens seed shells (abundantly available agricultural waste) were processed, treated and activated using $60 \%$ orthophosphoric acid for removal of congo red and malachite green from an aqueous solution. Its physicochemical properties and its removal efficiencies on the textile dyes were determined. The effect of particle size, adsorbent dose, initial $\mathrm{pH}$ of solution, adsorbate concentration and contact time on the process of adsorption was investigated. The equilibrium, kinetic and thermodynamic properties of the dyes removal were also investigated. The experimental data were modeled using linear regression method of analysis. The correlation coefficient was used as a criterion for model adequacy and acceptance. Sum of squares error was used to validate the isotherm models. The pseudo second-order kinetic model was found to best correlate the experimental data. The intraparticle diffusion is not the only rate controlling step in the process. The experimental data were found to follow the Langmuir, Freundlich and Tempkin isotherm models. The negative free energy indicated that the adsorption processes were spontaneously feasible. The process of adsorption has been found to be endothermic in nature. The removal of malachite green was found to be more spontaneous and feasible than the removal of congo red on the adsorbent. From the study it was deduced that the Mucuna pruriens seed shells activated with phosphoric acid were found to be a good adsorbent for the treatment of textile wastewater containing congo red and malachite green.
\end{abstract}

\section{Keywords}

Adsorption, Congo Red, Isotherm, Kinetics, Malachite Green, Mucuna pruriens Seed Shells, Thermodynamics

\footnotetext{
${ }^{*}$ Corresponding author.
}

How to cite this paper: Igwegbe, C.A., Onyechi, P.C., Onukwuli, O.D. and Nwokedi, I.C. (2016) Adsorptive Treatment of Textile Wastewater Using Activated Carbon Produced from Mucuna pruriens Seed Shells. World Journal of Engineering and Technology, 4, 21-37. http://dx.doi.org/10.4236/wjet.2016.41003 


\section{Introduction}

Color is the first pollutant to be known in wastewater [1]. Water pollution due to discharge of coloured effluents from textile dye manufacturing and textile dyeing mills is one of the major environmental concerns in the world today [2]. The total dye consumption of the textile industry worldwide is more than $10^{7} \mathrm{~kg} / \mathrm{year}$ [3]. Congo red (CR) is benzedene based anionic dye [4] and malachite green (MG) is a cationic dye [5]. In aqueous solution, anionic dyes carry a net negative charge due to the presence of sulphonate $\left(\mathrm{SO}_{3}^{-}\right)$groups, while cationic dyes carry a net positive charge due to the presence of protonated amine or sulfur containing groups [6]. Many dyes may cause allergic dermatitis, skin irritation, dysfunction of kidney, liver, brain, reproductive and central nervous system [7] [8]. The aquatic ecosystem can also be affected due to the toxicity of these dyes. A very low concentration of dye can make water unacceptable for various purposes [9]. Various techniques have been employed for the removal of textile dyes from wastewaters which include adsorption, nano-filtrtion, electro kinetic coagulation, coagulation and precipitation, advanced chemical oxidation, electrochemical oxidation, ozonation, supported liquid membrane, liquid-liquid extraction and biological process [10]. Adsorption has been shown to be one of the most promising and extensively used methods for the removal of both inorganic and organic pollutants from contaminated water [11]. The use of activated carbon has been highlighted as an effective technique for dye removal due to its unique molecular structure, high porosity and an extensive surface area [12]. Mucuna pruriens (Figure 1) is a tropical legume known as velvet bean or cowitch and by other common names, found in Africa, India and the Caribbean. The plant is an annual, climbing shrub with long vines that can reach over $15 \mathrm{~m}$ in length. The endocarp of Mucuna pruriens is non toxic. Mucuna pruriens is called ukpo by the Ibos in the southeast of Nigeria [7]. It is usually used as food thickeners [7].

Adsorption studies have been made using different agro based adsorbents on the removal of textile dyes such as Formosa papaya seed powder [13], cow bone [14], mangrove bark [3], ginger waste [5], and peanut shells [6].

The objective of this study is to investigate the isotherm, kinetics, and thermodynamics on congo red and malachite green removals using an abundant waste in Southeast Nigeria. The removal efficiencies of the activated Mucuna pruriens seed shells on the dyes at the same conditions will be compared.

\section{Experimental Materials and Methods}

\subsection{Preparation of the Adsorbent}

Mucuna pruriens seed shells (MSS) were collected from Mucuna pruriens seed processing, Ogbete market, Enugu state, Nigeria and washed thoroughly with de-ionized water to remove dirt, dried in the oven at $105^{\circ} \mathrm{C}$. The MSS were ground, sieved to the desired particle size of $1-2 \mathrm{~mm}$ and soaked in $60 \%$ orthophosphoric acid $\left(\mathrm{H}_{3} \mathrm{PO}_{4}\right)$ acid for 24 hours at room temperature and carbonized at $500^{\circ} \mathrm{C}$ for 2 hours using muffle furnace (Model $\mathrm{SX}-2.5-10)$. The carbonized samples were washed with de-ionized water until $\mathrm{pH} 7$, filtered and dried in the

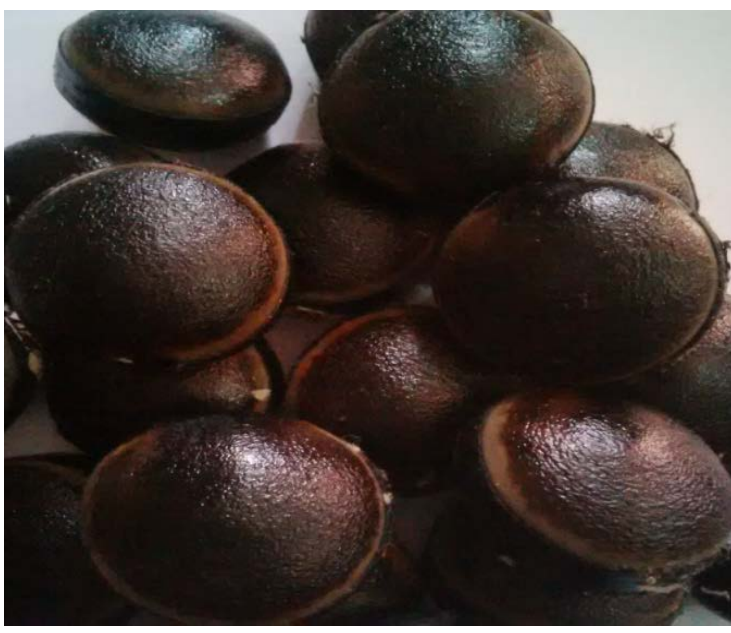

(a)

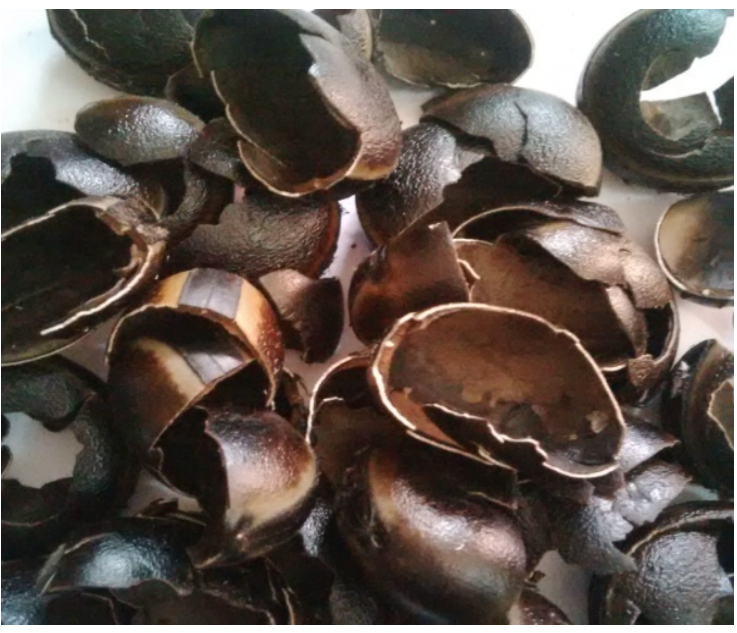

(b)

Figure 1. (a) (b) Mucuna pruriens seeds and shells respectively. 
oven at $105^{\circ} \mathrm{C}$ for 8 hours. The dried sample was allowed to cool to room temperature, sieved to different particle sizes and stored in air tight container for adsorption studies.

\subsection{Characteristics of the Adsorbents}

The physicochemical properties of the adsorbent (AMSS) were determined using the standard methods described by [15]. X-ray Fluorescence (XRF) was used to determine the oxides present in the Mucuna pruriens seed shells (MSS) using XRF spectrometer (Munipal 4 model). The Fourier transforms infrared (FTIR) was used to determine the functional groups present in MSS and AMSS using Shimadzu S8400 spectrophotometer, with samples prepared by the conventional $\mathrm{KBr}$ disc method. X-ray diffraction (XRD) was used to determine the diffraction pattern and inter planar spacing of AMSS. XRD patterns of the carbon was obtained on a powder X-ray diffractometer (Stchmabzu model 6000) with $\mathrm{CuK} \alpha$ radiation having a scanning speed of $8.000 \mathrm{deg} / \mathrm{min}$ and tested at $40.0 \mathrm{kV}$ and $30 \mathrm{~mA}$. The patterns were recorded over a 2-theta (2 $\theta)$ range of $2.0000-60.0000 \mathrm{deg}$. Scanning Electron Microscopy (SEM) was used to determine the surface morphology of MSS and AMSS.

\subsection{Adsorption Studies}

Congo red (CR) and malachite green (MG) of analytical grade were used without further purification. The reagents were of high grade. $0.1 \mathrm{~g}$ of each dye was dissolved in $1000 \mathrm{ml}$ of de-ionized water to get a dye solution of $100 \mathrm{mg} / \mathrm{l}$. Dye adsorption experiments were performed by taking $100 \mathrm{ml}$ stock solution of dye and treated with a known dose of adsorbent at $120 \mathrm{rev} / \mathrm{min}$. After a desired time of treatment, the dye solution was centrifuged and the concentration of the residue was determined using UV-Vis spectrophotometer (Model UV 754) at wavelength, $\lambda_{\max }$ of 498 and $617 \mathrm{~nm}$ for CR and MG respectively. The effects of particle size, $\mathrm{pH}$, adsorbent dose, concentration and contact time on the process of adsorption were investigated in the range of $0.3-1.5 \mathrm{~mm}, 2$ 10, $0.2-2.0 \mathrm{~g}, 100-500 \mathrm{mg} / \mathrm{l}$ and $10-150 \mathrm{~min}$ respectively. The percentage adsorbed was investigated by varying a parameter and keeping the other parameters constant. The amount of dye adsorbed per unit mass of activated carbon (mg/g) and percentage adsorbed (\%) were obtained as follows:

$$
\begin{gathered}
q_{e}=\frac{\left(C_{o}-C_{e}\right) V}{W} \\
\text { Percentage adsorded }=\frac{C_{o}-C_{e}}{C_{o}} \times 100
\end{gathered}
$$

where $C_{o}$ is the initial concentration of dye in the solution $(\mathrm{mg} / \mathrm{l}) ; C_{e}$ is the final concentration of dye in the solution (mg/l); $V$ is the volume of the solution (l); and $W$ is the weight of activated carbon (g).

The correlation coefficient $\left(\mathrm{R}^{2}\right)$ was used to determine the conformity, applicability and acceptance of the isotherm and kinetic models. The sum of the squares error (SSE \%) was also used to determine the adequacy of fit of the isotherm models. The higher the $\mathrm{R}^{2}$ value and the lower the value of SSE (\%) are, the better the conformity and adequacy of fit of the model are. The SSE was estimated using the expression [16]:

$$
\operatorname{SSE}(\%)=\frac{\left[\sum\left(q_{e(\exp )}-q_{e(\mathrm{cal})}\right)^{2}\right]^{0.5}}{N}
$$

where $N$ is the number of the data points used in each kinetic model plot.

\section{Results and Discussion}

\subsection{Physicochemical Properties of the Adsorbents}

The physicochemical properties of the adsorbent are presented in Table 1. The AMSS was found to have a high surface area indicating its high adsorptive performance. The adsorbent was also found to have a high percentage fixed carbon and iodine number. The $\mathrm{pH}$ value is near neutral which will be helpful for the treatment of all cases of dye waste water and the carbons can also be used for drinking water purification [17]. The activated carbon 
Table 1. Physicochemical properties of AMSS.

\begin{tabular}{|c|c|}
\hline Property & Value \\
\hline Moisture content (\%) & 7.0 \\
\hline Ash content (\%) & 5.38 \\
\hline Volatile matter (\%) & 14.25 \\
\hline Fixed carbon (\%) & 80.37 \\
\hline Bulk density (g/cm²) & 0.45 \\
\hline pH & 7.3 \\
\hline Iodine number (mg/g) & 724.61 \\
\hline Surface area $\left(\mathrm{m}^{2} / \mathrm{g}\right)$ & 847.43 \\
\hline Yield & 25.7 \\
\hline
\end{tabular}

was found to have low ash content (5.38\%). If the ash content is high, it will interfere with the pore structure development and hence adsorption will be less [18]. X-ray Fluorescence (XRF) was used to determine the oxides present in the MSS. The oxides present in the adsorbent which may be attributed to adsorption study are shown in Table 2. The oxides of calcium, potassium, iron and phosphorus are the major constituents of the adsorbents indicating that the Mucuna pruriens seeds can be a source of obtaining useful elements. The FTIR analysis was used to examine the surface functional groups of the adsorbent and to identify those groups responsible for dye adsorption. The FTIR spectra of MSS and AMSS are shown in Figure 2 and Figure 3 (plot of IR transmittance against wave number). Their frequencies of the bands and the corresponding functional groups are presented in Table 3 and Table 4. The O-H stretch in alcohols which is a very strong and broad bond can be detected in the carbons which are important adsorption sites. The modifications in the frequencies of the bands present in MSS may be as a result of chemical activation and reactions with O-H groups. Some of the bands and intensities were shifted or removed and new peaks were also detected after reaction with the activating agent $\left(\mathrm{H}_{3} \mathrm{PO}_{4}\right)$ indicating a change in the crystalline structure of the carbon (MSS). Xray diffraction (XRD) has been used to determine the diffractive pattern present on AMSS. The XRD spectrum of the carbons showed broad peaks (Figure 4), which indicates the presence of high content of amorphous form of carbon and little amounts of crystalline materials in the adsorbents. The three strongest peaks present in AMSS, with their interplanar

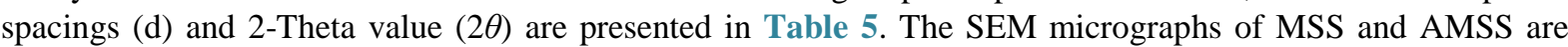
presented as Figure 5 and Figure 6 respectively. Both SEM figures seem showed that $\mathrm{H}_{3} \mathrm{PO}_{4}$ activation increased the surface area of MSS. The SEM of AMSS (Figure 6) seems to be threadlike with, some breakage in nature and dotted illuminations.

\subsection{Batch Adsorption Studies}

\subsubsection{Effect of Particle Size}

The effect of particle size is shown in Figure 7. The percentage of CR and MG adsorbed decreased with increase in particle size of the adsorbents. This may be as a result of decreasing the particle size improves the pores available for adsorption.

\subsubsection{Effect of Initial pH of Solution}

Figure 8 shows that higher uptakes of CR and MG by AMSS was obtained at pH of 2 and 10 respectively. The reduction in adsorption capacity of CR dye on AMSS with increasing $\mathrm{pH}$ can be attributed to change in surface characteristics and charge. Also negatively charged surface site on the adsorbent does not favour the adsorption of anionic dye (CR) ions due to electrostatic repulsion and abundance of $\mathrm{OH}^{-}$ion [19]. The increase in the percentage adsorbed as the $\mathrm{pH}$ was increased may be caused by the electrostatic interaction between negatively charge adsorbent and cationic MG [5]. The best $\mathrm{pH}$ for each dye adsorption was used for further studies.

\subsubsection{Effect of Adsorbent Dose}

The percentage of the dyes adsorbed increased as the adsorbent dose was increased until saturation point was 
Table 2. XRF results of MSS.

\begin{tabular}{cc}
\hline Chemical constituent & Composition (\%) \\
$\mathbf{C a O}$ & 44.9 \\
$\mathbf{K}_{2} \mathbf{O}$ & 22.1 \\
$\mathbf{F e}_{2} \mathbf{O}_{3}$ & 11.5 \\
$\mathbf{P}_{2} \mathbf{O}_{5}$ & 10.4 \\
$\mathrm{TiO}_{2}$ & 1.80 \\
$\mathrm{MnO}$ & 1.30 \\
$\mathbf{Z n O}$ & 0.57 \\
$\mathbf{R e}_{2} \mathbf{O}_{7}$ & 0.34 \\
$\mathrm{SO}_{3}$ & 0.30 \\
$\mathrm{CuO}$ & 0.27 \\
\hline
\end{tabular}

Table 3. Fourier transform infrared spectrum for MSS.

\begin{tabular}{ccc}
\hline Wave number $\left(\mathbf{c m}^{-1}\right)$ & Bond source & Functional group \\
\hline $\mathbf{5 0 7 . 3 0}$ & C-Br stretch & Alkyl halides \\
$\mathbf{6 4 4 . 2 5}$ & C-Cl stretch & Alkyl halides \\
$\mathbf{8 7 5 . 7 1}$ & =C-H bend & Alkenes \\
$\mathbf{1 0 2 0 . 3 8}$ & C-N stretch & Aliphatic amines \\
$\mathbf{1 1 0 8 . 1 4}$ & C-N stretch & Aliphatic amines \\
$\mathbf{1 4 1 7 . 7 3}$ & C-H stretch & Alkanes \\
$\mathbf{1 5 3 9 . 2 5}$ & N-O asymmetric stretch & Nitro compounds \\
$\mathbf{2 2 7 4 . 1 5}$ & - $\equiv \equiv$ C-stretch & Alkynes \\
$\mathbf{3 4 2 8 . 5 8}$ & O-H stretch & Alcohols and phenols \\
$\mathbf{3 7 5 7 . 4 6}$ & O-H stretch & Alcohols and phenols \\
$\mathbf{3 8 6 2 . 5 8}$ & O-H stretch & Alcohols and phenols \\
$\mathbf{3 9 4 2 . 6 3}$ & O-H stretch & Alcohols and phenols \\
\hline
\end{tabular}

Table 4. Fourier transform infrared spectrum for AMSS.

\begin{tabular}{ccc}
\hline Wave number $\left(\mathbf{c m}^{-1}\right)$ & Bond source & Functional group \\
\hline $\mathbf{5 6 4 . 2 0}$ & C-Br stretch & Alkyl halides \\
$\mathbf{1 1 1 5 . 8 6}$ & C-N stretch & Aliphatic amines \\
$\mathbf{1 5 4 2 . 1 4}$ & $\mathrm{N}-\mathrm{O}$ asymmetric stretch & Nitro compounds \\
$\mathbf{2 2 7 2 . 2 2}$ & $-\mathrm{C} \equiv$ E C-stretch & Alkynes \\
$\mathbf{3 4 6 4 . 2 7}$ & O-H stretch & Alcohols and phenols \\
$\mathbf{3 6 3 5 . 9 4}$ & O-H stretch & Alcohols and phenols \\
$\mathbf{3 7 4 8 . 7 8}$ & O-H stretch & Alcohols and phenols \\
$\mathbf{3 8 5 2 . 9 4}$ & O-H stretch & Alcohols and phenols \\
\hline
\end{tabular}


Table 5. Interplanar spacing, d of Xrays reflections for AMSS.

\begin{tabular}{cc}
\hline $\mathbf{d}(\AA)$ & 2-Theta Value \\
\hline $\mathbf{9 . 0 4 4 4 5}$ & 9.7714 \\
$\mathbf{4 . 7 6 7 3 1}$ & 18.5972 \\
$\mathbf{4 . 4 5 5 1 4}$ & 19.9131 \\
\hline
\end{tabular}

\section{ĐSHIMADZU}

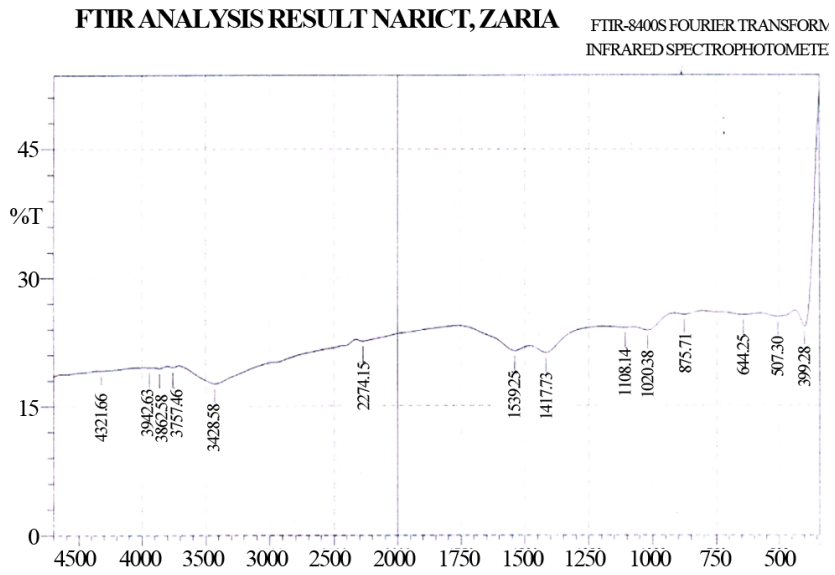

Figure 2. FTIR spectrum of MSS.

\section{円 SHIMADZU}

FIIR ANALYSIS RESULT NARICT, ZARIA FIIR-8400S FOURIERTRANSFORM INFRARED SPECTROPHOTOMETER

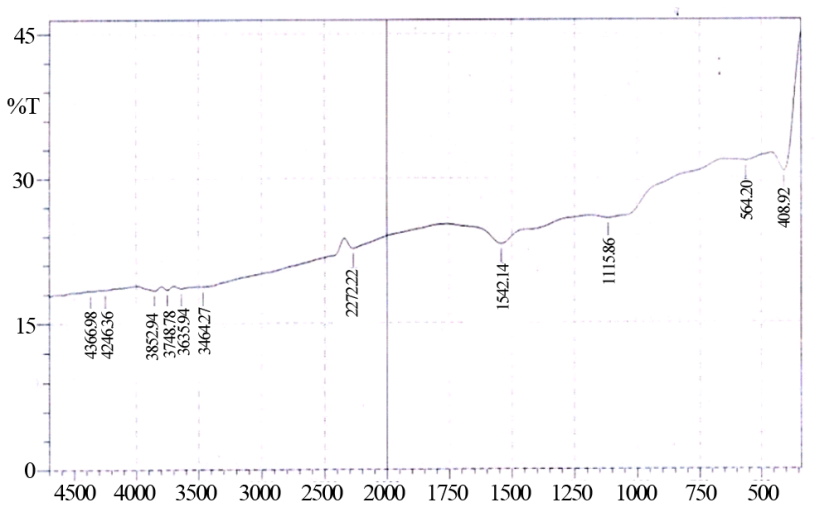

Figure 3. FTIR spectrum of AMSS.

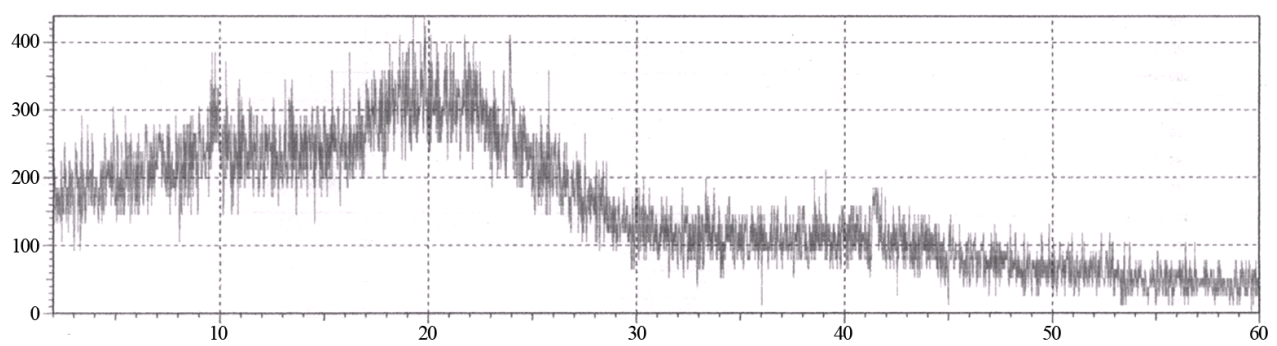

Figure 4. XRD profile of AMSS. 


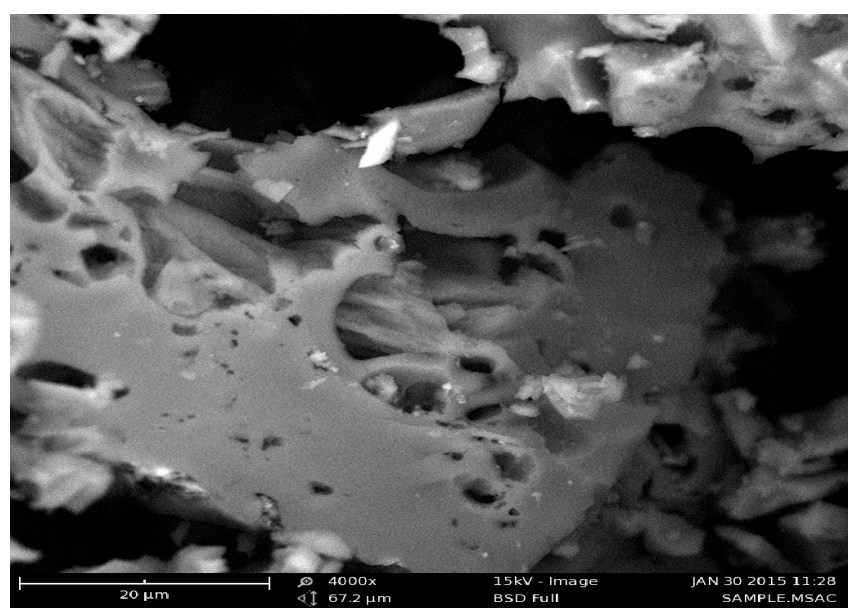

Figure 5. SEM image of MSS.

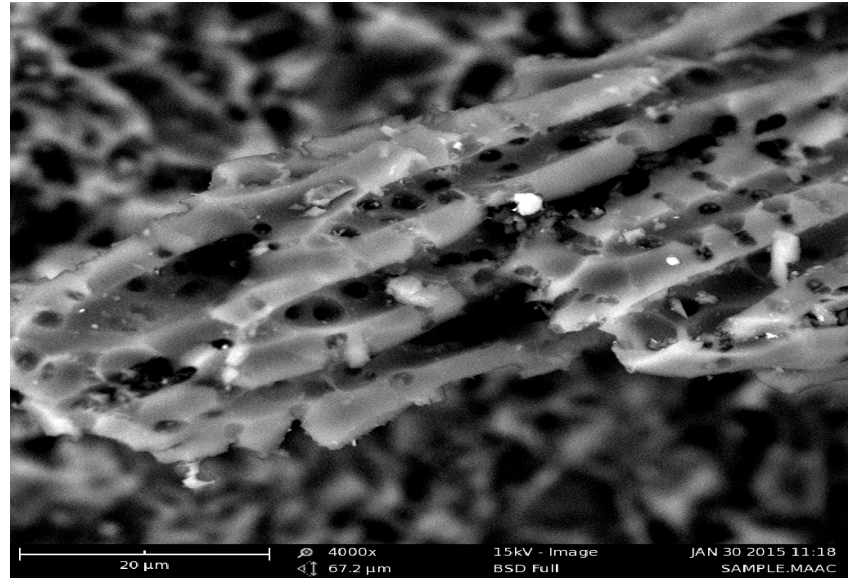

Figure 6. SEM image of AMSS.

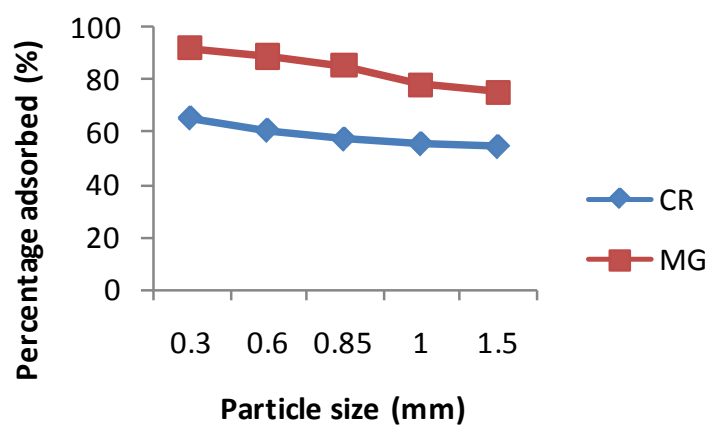

Figure 7. Effect of particle size on percentage adsorbed. Dosage = $1 \mathrm{~g}$, Concentration $=100 \mathrm{mg} / \mathrm{l}$, Time $=60 \mathrm{~min}$, Temperature $=303$ $\mathrm{K}$.

reached (Figure 9). This may be as a result of increase in the number of active sites available for the process of adsorption which nearly becomes constant as the dosage was increased further This may be due to sites remaining unsaturated during the adsorption process [20].

\subsubsection{Effect of Adsorbate Concentration}

Figure 10 depicts that the percentage removal of the textile dyes decreased as the adsorbate concentration was 


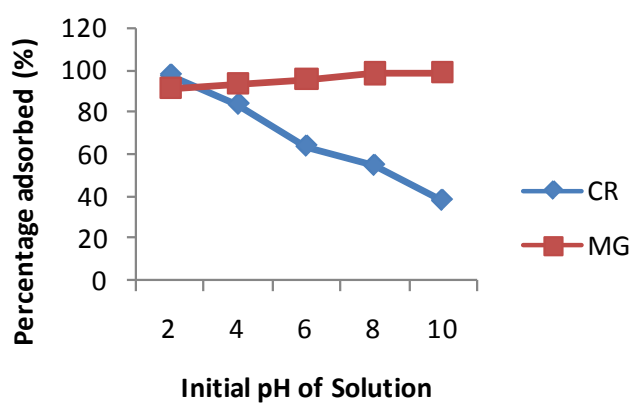

Figure 8. Effect of initial pH of solution on percentage adsorbed. Particle size $=0.30 \mathrm{~mm}$, Dosage $=1 \mathrm{~g}$, Concentration $=100 \mathrm{mg} / \mathrm{l}$, Time $=60 \mathrm{~min}$, Temperature $=303 \mathrm{~K}$.

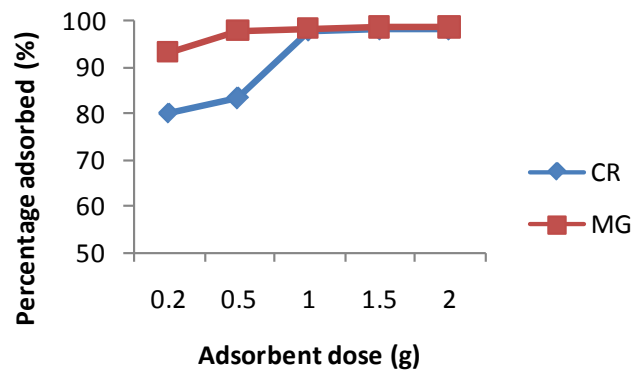

Figure 9. Effect of adsorbent dose on percentage adsorbed. Particle size $=0.30 \mathrm{~mm}, \mathrm{pH}(\mathrm{CR}=2, \mathrm{MG}=10)$, Concentration = $100 \mathrm{mg} / \mathrm{l}$, Time $=60 \mathrm{~min}$, Temperature $=303 \mathrm{~K}$.

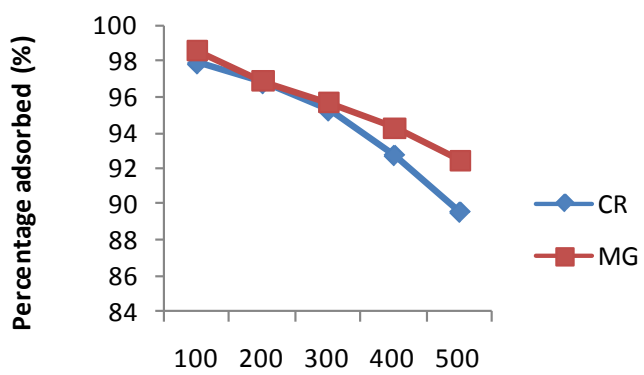

Adsorbate concentration $(\mathrm{mg} / \mathrm{l})$

Figure 10. Effect of adsorbate concentration. Particle size $=0.30$ $\mathrm{mm}, \mathrm{pH}(\mathrm{CR}=2, \mathrm{MG}=10)$, Dosage $=1 \mathrm{~g}$, Time $=60 \mathrm{~min}$, Temperature $=303 \mathrm{~K}$.

increased. This may be at higher concentration, the number of dye ions competing for the available sites on the surface of adsorbent was high resulting in high percentage adsorbed [21].

\subsubsection{Effect of Contact Time}

The percentage adsorbed increased with increase in contact time (Figure 11). The rate of removal of the textile dyes was rapid in the beginning due to the number of active sites available for the adsorption of dye ions and after a certain time, only a very low increment was observed.

\subsection{Adsorption Isotherm}

The equilibrium isotherm relationship between the concentration of the dyes in the liquid phase and the dyes in the adsorbent (AMSS) at a given temperature was studied. The results were analyzed using the Langmuir, Freundlich, Tempkin and Dubinin-Radushkevich isotherm. 


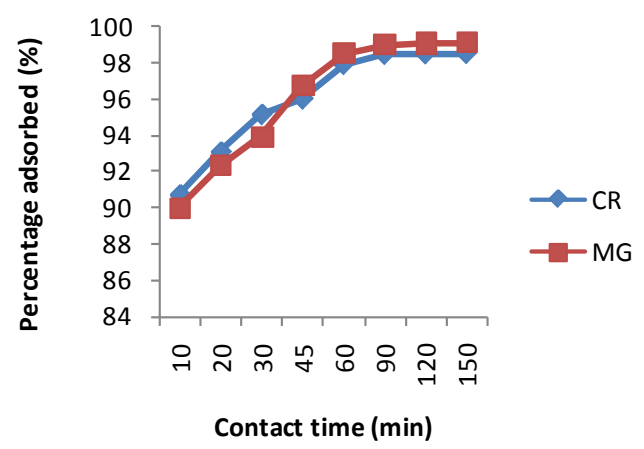

Figure 11. Effect of contact time on percentage adsorbed. Particle size $=0.30 \mathrm{~mm}, \mathrm{pH}(\mathrm{CR}=2, \mathrm{MG}=10)$, Dosage $=1 \mathrm{~g}$, Concentration $=100 \mathrm{mg} / \mathrm{l}$, Temperature $=303 \mathrm{~K}$.

\subsubsection{Langmuir Isotherm}

The Langmuir model is expressed as [22]:

$$
\frac{C_{e}}{q_{e}}=\frac{C_{e}}{Q_{m}}+\frac{1}{Q_{m} K_{L}}
$$

$C_{e}$ is the equilibrium concentration of dye (mg/l) and $q_{e}$ is the amount of the dye adsorbed (mg) per unit of activated carbon (g). $Q_{m}$ and $K_{L}$ are the Langmuir constants related to the adsorption capacity (mg/g) and the equilibrium constant $(\mathrm{l} / \mathrm{mg})$ respectively. The separation factor $\left(R_{L}\right)$ is a dimensionless constant used to predict whether an adsorption process is favourable or unfavourable which can be determined as follows [1]:

$$
R_{L}=\frac{1}{1+K_{L} C_{o}}
$$

where $K_{L}$ is a Langmuir constant. $R_{L}$ value implies the adsorption to be unfavourable $\left(R_{L}>1\right)$, linear $\left(R_{L}=1\right)$, favourable $\left(0<R_{L}<1\right)$, or irreversible $\left(R_{L}=0\right)$. The plot of $C_{e} / q_{e}$ against $C_{\mathrm{e}}$ is shown in Figure 12. The correlation coefficients $\left(\mathrm{R}^{2}\right)$ of 0.994 and 0.972 for $\mathrm{CR}$ and MG on AMSS respectively showed that the adsorption conformed to the Langmuir model. The separation factors, $R_{L}$ of 0.1632 and 0.0972 for CR and MG on AMSS respectively were found to be less than one indicating favourable adsorption (Table 6). The low SSE values of 0.747 and 1.071 for CR and MG on AMSS respectively indicates goodness of fit and adequacy of the model.

\subsubsection{Freundlich Isotherm}

Freundlich isotherm can be expressed as [16] [23]:

$$
q_{e}=K_{F} C_{e}^{\frac{1}{n}}
$$

This equation can be linearized as:

$$
\log q_{e}=\frac{1}{n} \log C_{e}+\log K_{F}
$$

The respective Freundlich constants, $n$ and $K_{F}$ (Table 6) were calculated from the slopes and intercepts of the linear plots (Figure 13) of $\log q_{e}$ versus $\log C_{e}$. The values of $K_{F}$ (measure of adsorption) increased with increasing temperature. The $\mathrm{R}^{2}$ values of 0.980 and 0.999 for CR and MG on AMSS respectively obtained shows that the adsorption on AMSS conformed to the Frendlich isotherm generally. The low SSE values of 0.947 and 0.258 for CR and MG respectively on AMSS indicates goodness of fit and adequacy of the model.

\subsubsection{Temkin Isotherm}

The Temkin isotherm is expressed as [24]:

$$
q_{e}=\frac{R T}{b_{T}} \ln \left(K_{T} C_{e}\right)
$$




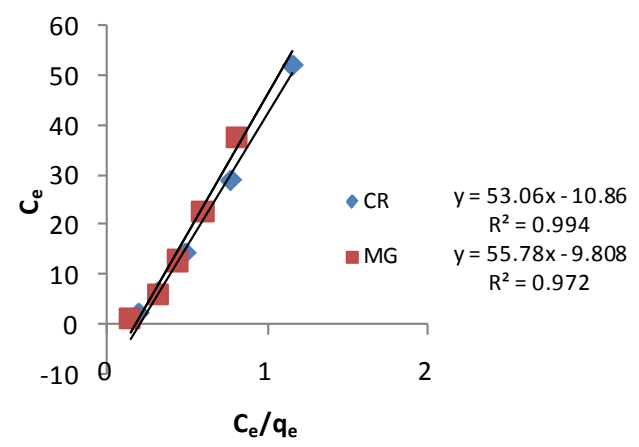

Figure 12. Langmuir isotherm model on CR and MG adsorption on AMSS.

Table 6. Calculated isotherm parameters for CR and MG adsorption on AMSS at $303 \mathrm{~K}$.

\begin{tabular}{|c|c|c|}
\hline Isotherm model & CR & MG \\
\hline \multicolumn{3}{|c|}{ Langmuir } \\
\hline$Q_{m}(m g / g)$ & 55.56 & 58.82 \\
\hline$K_{L}(L / m g)$ & 0.0869 & 0.0929 \\
\hline $\mathbf{R}_{\mathbf{L}}$ & 0.1632 & 0.0972 \\
\hline $\mathbf{R}^{2}$ & 0.994 & 0.972 \\
\hline SSE (\%) & 0.747 & 1.071 \\
\hline \multicolumn{3}{|c|}{ Freundlich } \\
\hline $\mathbf{n}$ & 2.1142 & 2.0704 \\
\hline$K_{f}(\mathrm{~L} / \mathrm{g})$ & 7.4989 & 8.1658 \\
\hline $\mathbf{R}^{2}$ & 0.980 & 0.999 \\
\hline SSE (\%) & 0.947 & 0.258 \\
\hline \multicolumn{3}{|c|}{ Tempkin } \\
\hline$b_{T}(\mathrm{~J} / \mathbf{m g})$ & 230.06 & 226.95 \\
\hline$K_{T}$ & 1.0356 & 1.2852 \\
\hline $\mathbf{R}^{2}$ & 0.992 & 0.953 \\
\hline SSE (\%) & 0.474 & 2.685 \\
\hline \multicolumn{3}{|c|}{ Dubinin-Radushkevich } \\
\hline$q_{D}(\mathrm{mg} / \mathrm{g})$ & 33.616 & 32.753 \\
\hline$B\left(\mathrm{~mol}^{2} / \mathrm{KJ}^{2}\right)$ & $5 \times 10^{-7}$ & $7 \times 10^{-7}$ \\
\hline$E(\mathrm{~kJ} / \mathrm{mol})$ & 0.0001 & 0.0001 \\
\hline $\mathbf{R}^{2}$ & 0.810 & 0.775 \\
\hline SSE (\%) & 4.129 & 5.820 \\
\hline
\end{tabular}

The linear form of this isotherm can be given by

$$
q_{e}=\frac{R T}{b_{T}} \ln K_{T}+\frac{R T}{b_{T}} \ln C_{e}
$$

$q_{e}$ is the amount adsorbed at equilibrium in $\mathrm{mg} / \mathrm{g} ; k_{1}$ is the Temkin isotherm energy constant. The constants $b_{T}$ which is related to the heat of adsorption and $K_{T}$ which is the equilibrium binding constant corresponding to the 


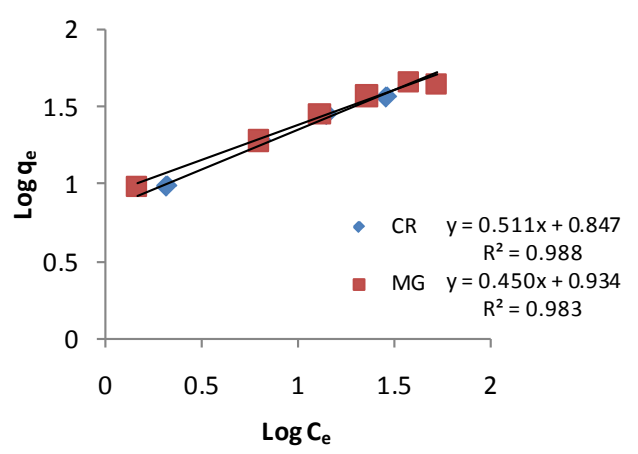

Figure 13. Freundlich isotherm model on CR and MG adsorption on AMSS.

maximum binding energy were determined from the plot of $q_{e}$ versus in $C_{e}$ (Figure 14). The constants are presented in Table 6. The high values of $b_{T}$ of 230.06 and $226.95 \mathrm{~J} / \mathrm{mg}$ for CR and MG on AMSS respectively indicate that the interaction between the adsorbate and the adsorbent was strong. The correlation coefficients, $\mathrm{R}^{2}$ value of 0.992 and 0.953 for CR and MG on AMSS respectively indicate that the isotherm model fitted well to the equilibrium adsorption experimental data. The low SSE values of 0.474 and 2.685 for CR and MG respectively on AMSS indicates goodness of fit and adequacy of the model.

\subsubsection{Dubinin-Radushkevich Isotherm}

The Dubinin-Radushkevich isotherm is given as [25]:

$$
\begin{gathered}
\ln q_{e}=\ln q_{D}-B \varepsilon^{2} \\
\varepsilon=R T \ln \left(1+1 / C_{e}\right) \\
E=1 /(2 B)^{0.5}
\end{gathered}
$$

where $q_{D}$ is the theoretical saturation capacity ( $\mathrm{mg} / \mathrm{g}$ ), $B$ is a constant related to mean free energy of adsorption per mole of the adsorbate $\left(\mathrm{mol}^{2} / \mathrm{J}^{2}\right), \varepsilon$ is the polanyi potential, $R$ is the universal gas constant $(8.314 \mathrm{~J} / \mathrm{mol} / \mathrm{K})$ and $T$ is the temperature in Kelvin and $E$ is the mean sorption energy. The D-R isotherm constants $B, q_{e}$ and $E$ were obtained (Table 6) from the linear plots of Inq against $\varepsilon^{2}$ (Figure 15). The correlation coefficients, $\mathrm{R}^{2}$ of 0.810 and 0.775 for CR and MG on AMSS respectively obtained showed that the experimental data obtained did not fit well to the D-R isotherm (Table 6). The removal of CR and MG on AMSS is not a physical process since the values of mean free energy (E) obtained were found to be $<8 \mathrm{KJ} / \mathrm{mol}$ [26]. The low SSE values of 4.129 and 5.820 for CR and MG respectively on AMSS indicates that the other isotherm models fit the experimental data more than this model.

\subsection{Kinetics of Adsorption}

The adsorption kinetics was studied in order to study the mechanism of the process of adsorption.

\subsubsection{Pseudo First-Order Kinetic Model}

The pseudo-first-order Lagergren equation is given by [16] [21]:

$$
\log \left(q_{e}-q_{t}\right)=\log q_{e}-\frac{K_{1}}{2.303} t
$$

where $q_{t}$ and $q_{e}$ are the amounts of dye adsorbed at time $t$ and equilibrium respectively and $K_{1}\left(\mathrm{~min}^{-1}\right)$ is the pseudo-first-order rate constant for the process of adsorption. $K_{1}$ and $q_{e}$ were determined from the slope and intercept of the plot of $\log \left(q_{e}-q_{t}\right)$ versus $t$ (Figure 16). The pseudo first order rate constants, $K_{1}$ is given in Table 7. The values of the correlation coefficients $\left(\mathrm{R}^{2}\right)$ of 0.928 and 0.959 for CR and MG respectively indicate that the removal of CR on AMSS did not follow the pseudo first-order kinetic model while MG removal on AMSS 


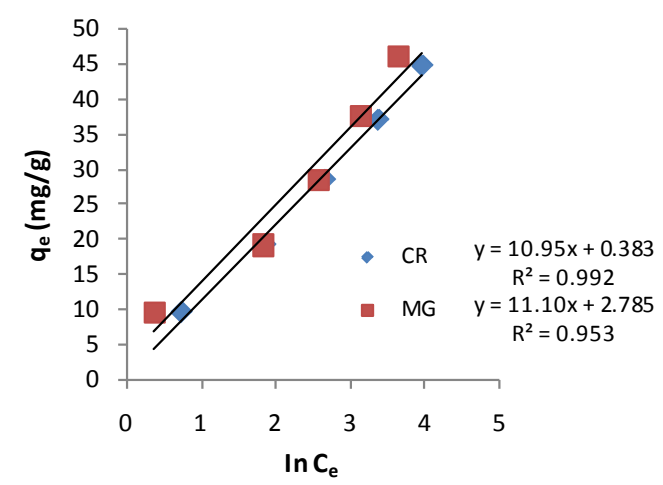

Figure 14. Temkin isotherm model on CR and MG adsorption on AMSS.

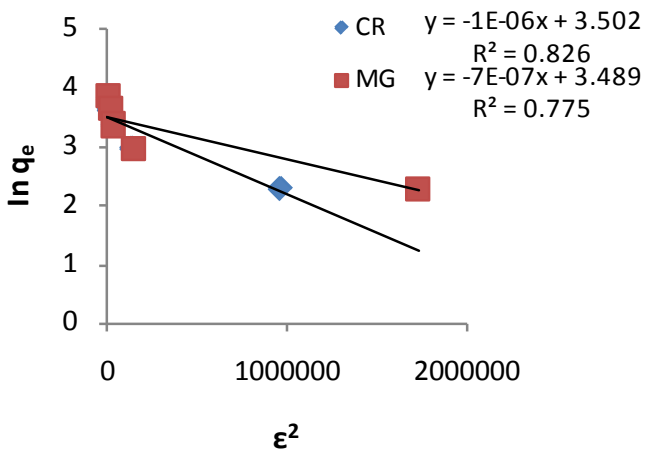

Figure 15. Dubinin Ruduskevich isotherm model on CR and MG adsorption on AMSS.

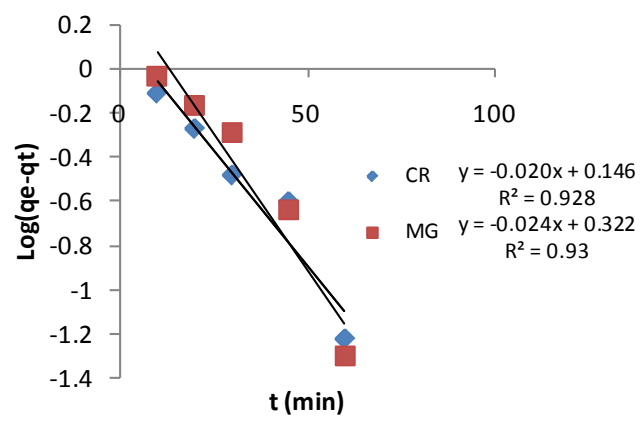

Figure 16. Pseudo-first order kinetic model on CR and MG adsorption on AMSS.

follow the pseudo first-order kinetic model.

\subsubsection{Pseudo Second-Order Kinetic Model}

The pseudo second - order adsorption kinetic equation is expressed as [27]:

$$
\frac{t}{q_{t}}=\frac{1}{k_{2}}+\frac{1}{q_{e}} t
$$

$k_{2}$ is the rate constant of pseudo second order adsorption (g/mg/min). The values of $k_{2}$ and $q_{e}$ (Table 7) were calculated from the plots of $t / q_{t}$ versus $t$ as shown in Figure 17. The $\mathrm{R}^{2}$ values which are close to unity (0.999) shows that the adsorption of CR and MG on AMSS is best described by the pseudo second-order mechanism suggesting that the rate-limiting step is a chemical adsorption [28]. 


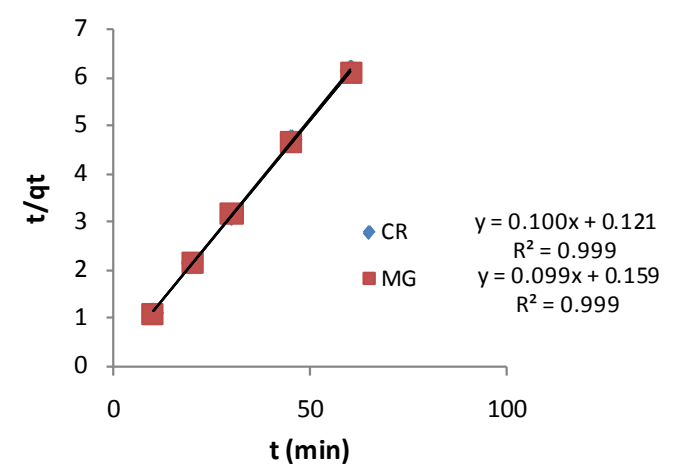

Figure 17. Pseudo-second order kinetic model on CR and MG adsorption on AMSS.

Table 7. Kinetic parameters and correlation coefficients obtained for the adsorption of CR and MG on AMSS at 303K.

\begin{tabular}{|c|c|c|}
\hline Kinetic model & CR & MG \\
\hline \multicolumn{3}{|c|}{ Pseudo first-order } \\
\hline$K_{1}\left(\min ^{-1}\right)$ & 0.0461 & 0.0438 \\
\hline$q_{e}(\mathrm{mg} / \mathrm{g})$ & 1.3996 & 1.7620 \\
\hline $\mathbf{R}^{2}$ & 0.928 & 0.959 \\
\hline \multicolumn{3}{|c|}{ Pseudo Second-order } \\
\hline$k_{2}(g / m g / m i n)$ & 0.0746 & 0.0537 \\
\hline$q_{e}(\mathrm{mg} / \mathrm{g})$ & 10.000 & 10.2041 \\
\hline $\mathbf{R}^{2}$ & 0.999 & 0.999 \\
\hline \multicolumn{3}{|c|}{ Elovich } \\
\hline$\alpha(\mathrm{mg} / \mathrm{g} / \mathrm{min})$ & 2.7473 & 2.1459 \\
\hline$\beta(\mathrm{g} / \mathrm{mg})$ & $2.47 \times 10^{9}$ & $1.30 \times 10^{7}$ \\
\hline $\mathbf{R}^{2}$ & 0.982 & 0.979 \\
\hline \multicolumn{3}{|c|}{ Intra particle and film diffusion } \\
\hline$k_{p i}\left(\mathbf{m g} \cdot \mathbf{g}^{-1} \cdot \min ^{-0.5}\right)$ & 0.123 & 0.160 \\
\hline$C_{i}$ & 8.760 & 8.532 \\
\hline $\mathbf{R}^{2}$ & 0.943 & 0.967 \\
\hline
\end{tabular}

\subsubsection{Elovich Model}

The Elovich kinetic model is expressed as [22]:

$$
\frac{t}{q_{t}}=\alpha \exp \left(-b q_{e}\right)
$$

Integration of this equation for the boundary conditions, gives:

$$
q_{t}=(1 / \beta) \ln (\alpha b)+(1 / \beta) \ln t
$$

where $\alpha$ is the initial adsorption rate $(\mathrm{mg} / \mathrm{g} \mathrm{min})$ and $\beta$ is related to the extent of surface coverage and the activation energy for chemisorptions (g/mg). A plot of $q_{t}$ versus $\ln t$ yielded a linear relationship (Figure 18) where the Elovich constants, $\beta$ and $\alpha$ were obtained and presented in Table 7. The adsorption of CR and MG on AMSS conformed to the Elovich kinetic model since the values of the linear regression coefficients $\left(\mathrm{R}^{2}\right)$ are 0.982 and 0.979 respectively (Table 6 ). 


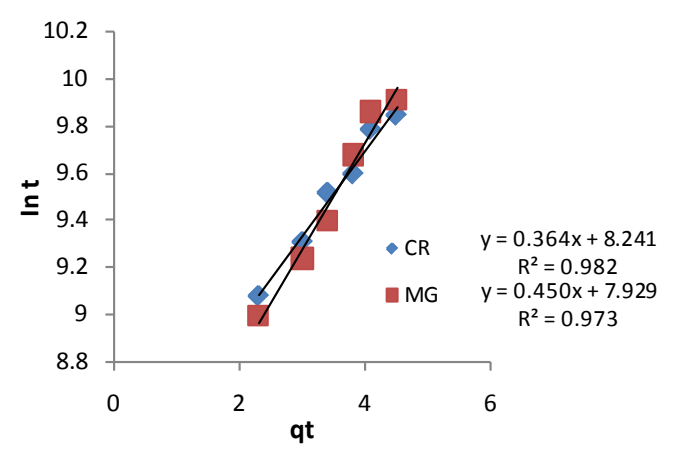

Figure 18. Elovich kinetic model on CR and MG adsorption on AMSS.

\subsubsection{Intraparticle Diffusion Kinetic Model}

The intraparticle diffusion model equation is given by [29]:

$$
q_{t}=k_{p i} t^{0.5}+C_{i}
$$

Where $k_{p i}$ is the rate parameter of stage $i$ and $C_{i}$ is the thickness of the boundary layer. The plot of $q_{t}$ versus $t^{0.5}$ (Figure 19) gives a straight line. The intraparticle diffusion is not the only rate controlling step involved in the adsorption of CR and MG by the adsorbent since its linear plots did not pass through the origin [26].

\subsection{Thermodynamics of Adsorption}

The activation energy was evaluated from the pseudo second-order kinetic rate constants obtained from adsorptive removals performed at 303, 313 and 323K. The Arrhenius equation is given as [30]:

$$
\ln k_{2}=\ln A-\frac{E a}{R T}
$$

where $k_{2}$ is the rate constant obtained from the pseudo second-order kinetic model (g/mg h), Ea is the Arrhenius activation energy of adsorption $(\mathrm{kJ} / \mathrm{mol})$ and $A$ is the Arrhenius factor. In $k_{2}$ was plotted against $1 / T$ and Ea was obtained from the slope. The activation energies of adsorption of CR on AMSS is $19.9182 \mathrm{~K} / \mathrm{Jmol}$ which implies that the rate-limiting step might be a physically controlled process since which is less than $40 \mathrm{~K} / \mathrm{Jmol}$ and MG adsorption on AMSS is $66.7789 \mathrm{~K} / \mathrm{Jmol}$ which is greater than $40 \mathrm{~K} / \mathrm{Jmol}$, might be a chemically controlled process [31].

Adsorption thermodynamics is the study of the effect of temperature on the process of adsorption. $\Delta G^{0}$ and $\Delta H^{0}$ were used to evaluate the spontaneity and nature of the adsorption process respectively [28]. The thermodynamic parameters free energy $\left(\Delta G^{0}\right)$, enthalpy $\left(\Delta H^{0}\right)$ and entropy $\left(\Delta S^{0}\right)$ were determined as follows [32]:

$$
\begin{aligned}
\ln K_{C} & =\frac{\Delta S^{0}}{R}-\frac{\Delta H^{0}}{R T} \\
\Delta G^{0} & =-R T \ln K_{C}
\end{aligned}
$$

where $R(8.314 \mathrm{~J} / \mathrm{mol} \mathrm{K})$ is the universal gas constant, $T(\mathrm{~K})$ is the solution temperature and $K_{L}(\mathrm{~L} / \mathrm{mg})$ is the Langmuir isotherm constant. The values of $\Delta H^{0}$ and $\Delta S^{0}$ were calculated, respectively from the slope and intercept of the Vant Hoff plot of $\ln K_{C}$ versus $1 / T$ (Figure 20) are presented in Table 8. The values of $\Delta G^{0}$ were found to be negative which decreased with increased temperature showing that the adsorption was more favourable and spontaneous at higher temperature (Table 8). The positive value of $\Delta H^{0}$ indicates the endothermic nature of the process. The positive value of $\Delta S^{0}$ indicates an increase in the randomness at the solid/solution interface due to the redistribution of energy between dyes and the adsorbents [23]. The removal of MG was found to be more spontaneous than the removal of CR on AMSS.

\section{Conclusion}

Activated carbon prepared from Mucuna pruriens seeds shells (abundantly available agricultural waste) using 


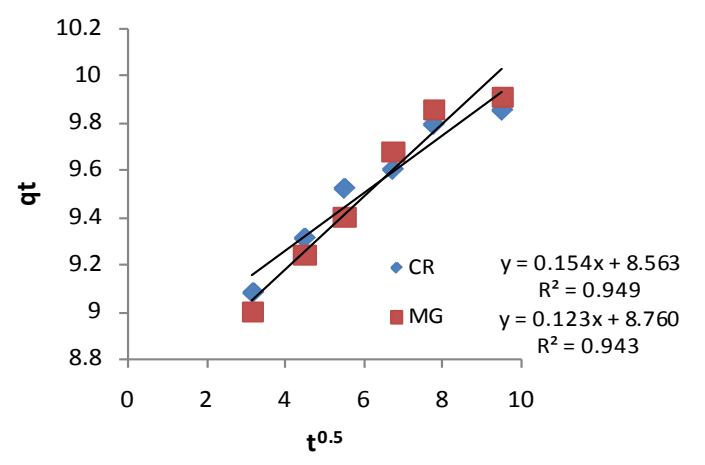

Figure 19. Intraparticle diffusion model on CR and MG adsorption on AMSS.

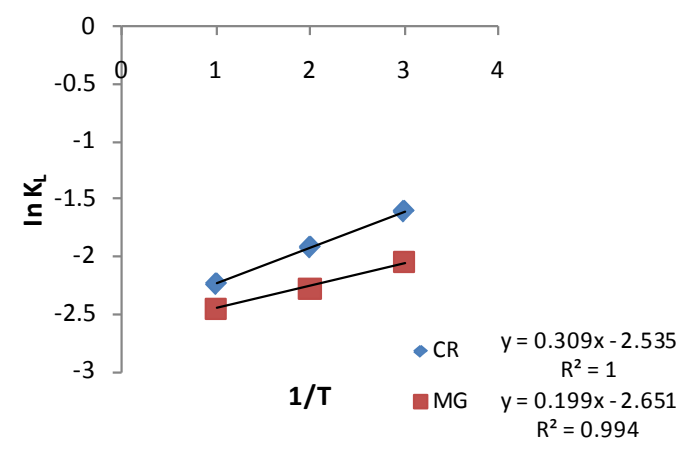

Figure 20. Vant Hoff plot on CR and MG adsorption on AMSS.

Table 8. Thermodynamic parameters for the adsorption of CR and MG dye on AMSS.

\begin{tabular}{|c|c|c|c|c|c|c|c|}
\hline \multirow{2}{*}{ Dye } & \multirow{2}{*}{$\begin{array}{c}E a \\
(\mathbf{K J} / \mathbf{m o l})\end{array}$} & \multirow{2}{*}{$\begin{array}{c}\Delta H^{0} \\
(\mathrm{KJ} / \mathrm{mol})\end{array}$} & \multirow{2}{*}{$\begin{array}{c}\Delta S^{0} \\
(\mathrm{~J} / \mathbf{K} / \mathbf{m o l})\end{array}$} & \multirow[t]{2}{*}{$\mathbf{R}^{2}$} & \multicolumn{3}{|c|}{$\begin{array}{c}\Delta G^{0} \\
(\mathrm{KJ} / \mathrm{mol})\end{array}$} \\
\hline & & & & & $303 \mathrm{~K}$ & $313 \mathrm{~K}$ & $323 \mathrm{~K}$ \\
\hline CR & 19.9182 & 16.453 & 33.880 & 1.000 & -10.249 & -10.588 & -10.927 \\
\hline MG & 66.7789 & 17.434 & 37.696 & 0.994 & -11.404 & -11.781 & -12.158 \\
\hline
\end{tabular}

Particle size $=0.3 \mathrm{~mm}$, Contact time $=60 \mathrm{~min}$, Initial concentration $=100 \mathrm{mg} / \mathrm{l}$ and adsorbent dose $=1 \mathrm{~g}$.

chemical activation was used for the removal of congo red and malachite green (textile dyes) from aqueous solution. The removal efficiencies of using $\mathrm{H}_{3} \mathrm{PO}_{4}$ activated carbon (AMSS) on CR and MG were compared. The batch adsorption studies indicated that the percentage adsorbed depended on particle size, adsorbent dose, $\mathrm{pH}$, contact time and adsorbate concentration. The adsorption of AMSS on CR and MG was found to follow the Langmuir, Freundlich and Tempkin isotherms. The pseudo second order kinetic was found to best correlate the experimental data obtained. The intraparticle diffusion is involved in the adsorption of CR and MG by the adsorbent but it is not the only rate controlling step. The negative free energy change $\left(\Delta G^{0}\right)$ and positive value of entropy $\left(\Delta S^{0}\right)$ indicate the feasible and spontaneous nature of the process. The removal of MG was found to be more spontaneous and feasible than the removal of CR on AMSS. AMSS was found to be a better adsorbent for MG removal than for CR. The thermodynamic and kinetics data can be further used for the design of a plant for treatment of industrial wastewater containing congo red and malachite green on large scale.

\section{Acknowledgements}

Authors are grateful to the Faculty of Engineering, Nnamdi Azikiwe University, Awka, Nigeria; National Research Institute for Chemical Technology (NARICT), Zaria, Nigeria; National Metallurgical Training Institute, Onitsha, Nigeria; and Scientific Equipment Development Institute (SEDI), Enugu, Nigeria. 


\section{References}

[1] Rangabhashiyam, S., Anu, N. and Selvaraju N. (2013) Sequestration of Dye from Textile Industry Wastewater Using Agricultural Waste Products as Adsorbents. Journal of Environmental Chemical Engineering, 1, 629-641. http://dx.doi.org/10.1016/j.jece.2013.07.014

[2] Mittal, A., Kurup, L. and Mittal, J. (2007) Freundlich and Langmuir Adsorption Isotherms and Kinetics for the Removal of Tartrazine from Aqueous Solutions Using Hen Feathers. Journal of Hazardous Materials, 146, $243-248$. http://dx.doi.org/10.1016/j.jhazmat.2006.12.012

[3] Tan, L.S., Jain, K. and Rozaini, C.A. (2010) Adsorption of Textile Dye from Aqueous Solution on Pretreated Mangrove Bark, an Agricultural Waste: Equilibrium and Kinetic Studies. Journal of Applied Sciences in Environmental Sanitation, 5, 283-294.

[4] Sivakumar1, V., Asaithambi, M., Sivakumar, P. and Gopal, N. (2014) Removal of Congo Red Dye Using an Adsorbent Prepared from Martynia annua, L. Seeds. American Chemical Science Journal, 4, 424-442. http://dx.doi.org/10.9734/ACSJ/2014/6680

[5] Ahmad, R. and Kumar, R. (2010) Adsorption Studies of Hazardous Malachite Green onto Treated Ginger Waste. Journal of Environmental Management, 91, 1032-1038. http://dx.doi.org/10.1016/j.jenvman.2009.12.016

[6] Abbas, A., Murtaza, S., Shahid, K., Munir, M., Ayub, R. and Akber, S. (2012) Comparative Study of Adsorptive Removal of Congo Red and Brilliant Green Dyes from Water Using Peanut Shell. Middle-East Journal of Scientific Research, 11, 828-832.

[7] Onyechi, C.A. (2014) Textile Wastewater Treatment Using Activated Carbon from Agro Wastes. M. Eng. Thesis, Department of Chemical Engineering, Nnamdi Azikiwe University, Awka.

[8] Salleh, M.A.M., Mahmoud, D.K., Karim, W.A.W.A. and Idris, A. (2011) Cationic and Anionic Dye Adsorption by Agricultural Solid Wastes: A Comprehensive Review. Desalination, 280, 1-13. http://dx.doi.org/10.1016/j.desal.2011.07.019

[9] Maurya, N.S., Mittal, A.K. and Cornel, P. (2008) Evaluation of Adsorption Potential of Adsorbents: A Case of Uptake of Cationic Dyes. Journal of Environmental Biology, 29, 31-36.

[10] Mahmoud, A.S., Ghaly, A.E. and Brooks, M.S. (2007) Removal of Dye from Textile Wastewater Using Plant Oils under Different pH and Temperature Conditions. American Journal of Environmental Science, 3, 205-218. http://dx.doi.org/10.3844/ajessp.2007.205.218

[11] Prasad, A.L. and Santhi, T. (2012) Adsorption of Hazardous Cationic Dyes from Aqueous Solution onto Acacia nilotica Leaves as an Eco Friendly Adsorbent. Sustainable Environmental Research, 22, 113-122.

[12] Isah, U.A. and Gatawa, A.I. (2012) A Kinetic Study of the Adsorption of Reactive Yellow 21 Dye on Flamboyant Shells Activated Carbon. Advances in Applied Science Research, 3, 4036-4040.

[13] Pavan, F.A., Camacho, E.S., Lima, E.C., Dotto, G.L., Branco, V.T.A. and Dias, S.L.P. (2014) Formosa Papaya Seed Powder (FPSP): Preparation, Characterization and Application as an Alternative Adsorbent for the Removal of Crystal Violet from Aqueous Phase. Journal of Environmental Chemical Engineering, 2, 230-238. http://dx.doi.org/10.1016/j.jece.2013.12.017

[14] Salh, D.M. (2014) Adsorption of Malachite Green and Methyl Green on Cow Bone. Journal of Environment and Earth Science, 4, 50-56.

[15] Nwabanne, J.T. and Igbokwe, P.K. (2012) Preparation of Activated Carbon from Nipa Palm Nut: Influence of Preparation Conditions. Research Journal of Chemical Sciences, 1, 53-58.

[16] Taha, M.E. (2011) Equilibrum Isotherms and Kinetic Studies of Removal of Methylene Blue Dye by Adsorption onto Miswak Leaves as Natural Adsorbent. Journal of Environmental Protection, 2, 817-827. http://dx.doi.org/10.4236/jep.2011.26093

[17] Baseri, J.R., Palanisamy, P.N. and Sivakumar, P. (2012) Preparation and Characterization of Activated Carbon from Thevetia peruviana for the Removal of Dyes from Textile Waste Water. Advanced Applied Science Research, 3, 377 383.

[18] Devi, B.V., Jahagirdar, A.A. and Ahmed, M.N.Z. (2012) Adsorption of Chromium on Activated Carbon Prepared from Coconut Shell. International Journal of Engineering Research and Applications, 2, 364-370.

[19] Zawani, Z., Luqman, C.A. and Chong, S.Y. (2009) Equilibrum Kinetics and Thermodynamics Studies: Adsorption of Ramazol Black 5 on the Palm Kernel Shell Activated Carbon (PKS-AC). European Journal of Scientific Research, 37, 67-76.

[20] Taha, D.N., Samaka, I.S. and Mohammed, L.A. (2013) Adsorptive Removal of Dye from Industrial Effluents Using Natural Iraqi Palygorskite Clay as Low-Cost Adsorbent. Journal of Asian Science Research, 3, 945-955. 
[21] Nwabanne, J.T. and Igbokwe, P.K. (2012) Thermodynamic and Kinetic Behaviors of Lead (II) Adsorption on Activated Carbon Derived from Palmyra Palm Nut. International Journal of Applied Science and Technology, 2, 245-254.

[22] Okoye, A.I., Ejikeme, P.M. and Onukwuli, O.D. (2010) Lead Removal from Wastewater Using Fluted Pumpkin Seed Shell Activated Carbon: Adsorption Modeling and Kinetics. International Journal of Environmental Science and Technology, 7, 793-800. http://dx.doi.org/10.1007/BF03326188

[23] Igwegbe, C.A., Onyechi, P.C. and Onukwuli, O.D. (2015) Kinetic, Isotherm and Thermodynamic Modeling on the Adsorptive Removal of Malachite Green on Dacryodes edulis Seeds. Journal of Scientific and Engineering Research (An International Journal), 2, 23-39.

[24] Gautam, R.K., Mudhoo, A., Lofrano, G. and Chattopadhyaya, M.C. (2014) Biomass-Derived Biosorbents for Metal Ions Sequestration: Adsorbent Modification and Activation Methods and Adsorbent Regeneration. Journal of Environmental Chemical Engineering, 2, 239-259. http://dx.doi.org/10.1016/j.jece.2013.12.019

[25] Ramachandran, P., Vairamuthu, R. and Ponnusamy, S. (2011) Adsorption Isotherms, Kinetics, Thermodynamics and Desorption Studies of Reactive Orange16 on Activated Carbon Derived From Ananas comosus (L.) Carbon. Journal of Engineering and Applied Sciences, 6, 15-26.

[26] Boparai, H.K., Joseph, M. and O’Carroll, D. (2011) Kinetics and Thermodynamics of Cadmium Ion Removal by Adsorption onto Nano Zero-Valent Iron Particles. Journal of Hazardous Materials, 186, 458-465. http://dx.doi.org/10.1016/j.jhazmat.2010.11.029

[27] Ahmad, M.A., Herawan, S.G. and Yusof, A.A. (2014) Equilibrium, Kinetics, and Thermodynamics of Remazol Brilliant Blue R Dye Adsorption onto Activated Carbon Prepared from Pinang Frond. Mechanical Engineering, 2014, Article ID: 184265. http://dx.doi.org/10.1155/2014/184265

[28] Al-Ghouti, M., Khraisheh, M.A.M., Ahmad, M.N.M. and Allen, S. (2005) Thermodynamic Behaviour and the Effect of Temperature on the Removal of Dyes from Aqueous Solution Using Modified Diatomite: A Kinetic Study. Journal of Colloid Interface Science, 287, 6-13. http://dx.doi.org/10.1016/j.jcis.2005.02.002

[29] Thilagavathi, M., Arivoli, S. and Vijayakumaran, V. (2014) Kinetic and Thermodynamic Studies on the Adsorption Behavior of Rhodamine B Dye Using Prosopis juliflora Bark Carbon. Scholars Journal of Engineering and Technology, 2, 258-263.

[30] Eren, E., Cubuk, O., Ciftci, H., Eren, B. and Caglar, B. (2010) Adsorption of Basic Dye from Aqueous Solutions by Modified Sepiolite: Equilibrium, Kinetics and Thermodynamics Study. Desalination, 252, 88-96. http://dx.doi.org/10.1016/j.desal.2009.10.020

[31] Abramian, L. and El-Rassy, H. (2009) Adsorption Kinetics and Thermodynamics of Azo-Dye Orange II onto Highly Porous Titania Aerogel. Chemical Engineering Journal, 150, 403-410. http://dx.doi.org/10.1016/j.cej.2009.01.019

[32] Babakhouya, N., Boughrara, S. and Abad, F. (2010) Kinetics and Thermodynamics of Cd (II) Ions Sorption on Mixed Sorbents Prepared from Olive Stone and Date Pit from Aqueous Solution. American Journal of Environmental Sciences, 6, 470-476. http://dx.doi.org/10.3844/ajessp.2010.470.476 